\title{
Effect of low-level laser intervention on dermatitis symptoms and cytokine changes in DNCB-induced atopy mouse model: A randomized controlled trial
}

\author{
YOU LIM KIM ${ }^{1,2^{*}}$, HEE SUNG LIM ${ }^{3 *}$ and SUK MIN LEE ${ }^{2}$ \\ ${ }^{1}$ Division of Healthcare Technology Assessment Research, National Evidence-based Healthcare Collaborating Agency, \\ Seoul 04554; ${ }^{2}$ Department of Physical Therapy, Sahmyook University, Seoul 01795; \\ ${ }^{3}$ Department of Physical Education, College of Sport of Science, Korea National Sport University, \\ Seoul 05541, Republic of Korea
}

Received May 7, 2019; Accepted May 7, 2021

DOI: $10.3892 / \mathrm{etm} .2021 .10630$

\begin{abstract}
The incidence of atopic dermatitis (AD) has recently increased due to various factors. Its prevalence is higher among children and teenagers than in other age groups. Numerous methods to treat AD are available, including light ray therapy, which has been proposed as an alternative therapy for the treatment of AD. The present study aimed to evaluate the curative mechanism and optimal energy level of energy irradiation from a low-level laser (LLL) toward AD. AD was induced in BALB/c mice with dinitrochlorobenzene (DNCB) solution. The mice were divided into six groups, including one normal control $(n=8)$, one AD control $(n=10)$ and four AD experimental groups with LLL irradiation at $2 \mathrm{~J} / \mathrm{cm}^{2}(\mathrm{n}=10)$, $4 \mathrm{~J} / \mathrm{cm}^{2}(\mathrm{n}=10), 6 \mathrm{~J} / \mathrm{cm}^{2}(\mathrm{n}=9)$ and $8 \mathrm{~J} / \mathrm{cm}^{2}(\mathrm{n}=10)$. Following AD induction, an LLL was applied to the four AD experimental groups for 2, 4, 6, and $8 \mathrm{~min}$, for two weeks (14 times in total) at a wavelength of $650 \mathrm{~nm}$ and an output of $50 \mathrm{~mW}$. The effects of irradiation on AD were evaluated using a scratch test, a clinical skin severity test, immunoglobulin-E (IgE) analysis and measurements of numerous cytokine levels, including interleukin (IL)-4, IL-6, tumor necrosis factor (TNF)- $\alpha$, and interferon- $\gamma($ IFN- $\gamma)$, tissue thickness and mast cell count. The results demonstrated that serum IgE level in all irradiated groups was significantly decreased compared with that of the AD control group, and IL-4 level was significantly decreased in all irradiated groups apart from the $8 \mathrm{~J} / \mathrm{cm}^{2} \mathrm{LLL}$ irradiated group. IL-6 and TNF- $\alpha$ levels were also significantly decreased in all irradiated groups. The results from histological analysis
\end{abstract}

Correspondence to: Dr Suk Min Lee, Department of Physical Therapy, Sahmyook University, 26-21 Gongneung 2-dong, Nowon-gu, Seoul 01795, Republic of Korea

E-mail: leesm@syu.ac.kr

*Contributed equally

Key words: low-level laser, atopic dermatitis, therapy, mice, dermatology revealed diminished epidermal thickness and mast cell counts in irradiated mice compared with those mice in the AD control group. In summary, these findings suggested that LLL irradiation may alleviate symptoms of AD and may be useful for restoring cytokines levels and tissues features to normal levels.

\section{Introduction}

Atopic dermatitis (AD) is a complex disease (1) caused by numerous environmental factors, such as stress from various types of environmental pollution, immunological factors (2), including increased serum immunoglobulin-E (IgE) levels and imbalance between T helper type 1 (Th1) and Th2 cells, and genetic factors $(3,4)$. Th2 cells secrete cytokines, including interleukin (IL)-4, IL-5, IL-6, and IL-10, and are therefore involved in humoral immunity, while Th1 cells secrete interferon (IFN) $-\gamma$ and IL-2, which are involved in cellular immunity. In AD, the levels of IL-4, IL- 6 and tumor necrosis factor- $\alpha$ (TNF- $\alpha$ ) tend to increase, whereas IFN- $\gamma$ level tends to decrease (5). Furthermore, the number of Langerhans cells and activation of mast cells are increased in $\mathrm{AD}(6)$.

The main treatments for AD include local steroids, antihistamine creams and immunomodulators. Furthermore, IFN- $\gamma$-based drugs and immunosuppressants are typically administered. However, previous studies have focused on phototherapy, including UV phototherapy and infrared light emitting diode therapy (5,7-11).

Low-level laser (LLL) therapy (LLLT), which is a method using phototherapy, uses low power $(\leq 500 \mathrm{~mW})$ and produces minimal heat. Its therapeutic effect is mainly driven by the stimulation of cells with photo-energy $(12,13)$. In addition, unlike sunlight, LLLT has a narrow wavelength bandwidth, allowing emission from a specific light source to be directed onto a focused and localized area. This technique is therefore effective for the treatment of a specific area.

The effects of LLLT in human tissues are mainly driven by the absorption of energy by specific photoreceptors, such as porphyrin and cytochrome c oxidase. Absorption of energy by these receptors promotes intracellular oxygen synthesis, 
mitochondrial ATP synthesis, chemiosmosis, DNA replication and infiltration of $\mathrm{Ca}^{2+}$ into the cell cytoplasm (14). These effects subsequently promote cell proliferation and migration, increase tissue oxygenation and control cytokine concentration, growth factors and inflammation $(12,15)$. Furthermore, LLLT treatment increases blood flow to regenerate tissues, provides tension to the skin by promoting collagen production by fibroblasts, promotes cell division to stimulate cell growth, promotes bone regeneration and rearrangement, corrects abnormal hormones level and reduces pain (15-17). Based on these effects, numerous studies have reported that laser therapy displays some positive effects on several musculoskeletal diseases, rheumatoid arthritis, post-herpetic neuralgia, pain, inflammation, edema, cut wounds, nerve damage and neural regeneration (18-26).

Previous studies have examined the use of laser therapy in the treatment of AD (18,27-32). However, these studies used different types of laser and dosages and only demonstrated that laser therapy is clinically effective against AD. To the best of our knowledge, only few studies have thoroughly assessed the underlying mechanism of laser therapy therapeutic effect and suggested an optimal dosage.

The present study aimed to investigate the effects of LLLT on AD using clinical skin severity testing, scratch testing, total serum IgE and IL-4 level evaluation, as well as examined the gene expression of various cytokines (IL-4, IL- 6 , TNF- $\alpha$, IFN- $\gamma$ ), epidermal thickness and mast cell counts.

\section{Materials and methods}

Animals. All experimental procedures and animal handling were performed following approval from the animal research ethics board of Sahmyook University (approval no. SYUIACUC2017-004). A total of 71 4-week-old BALB/c mice (weight, 16-18 g) were purchased from the laboratory animal center of Hallym Co. (Gyeonggi, South Korea). Mice were acclimatized for seven days in the animal room at the Center for Neurological Sciences, Sahmyook University. Animals had free access to food and water, and the temperature, humidity and day-night cycle were automatically controlled at $23 \pm 2^{\circ} \mathrm{C}, 55 \pm 10 \%$ and a 12 -h cycle, respectively.

Sensitization and challenge. The backs of all the mice were shaved clean and a $24-\mathrm{h}$ recovery period was provided for the micro-wounds on the skin to heal. To induce AD, compound 1-chloro-2,4-di-nitrobenzene (DNCB; Sigma-Aldrich; Merck $\mathrm{KGaA}$ ) solution (at 2.5\%) was prepared by mixing acetone and olive oil in a 3:1 ratio to which DNCB was added. The compound DNCB solution (200 $\mu \mathrm{l}$; volume given on day 1) was applied to the backs of the mice to induce immune responses. From day 3, 1.0\% DNCB solution $(150 \mu \mathrm{l})$ was applied once every three days, and eschar formation and more severe scratching were observed by the second application of the solution. The eschars started to fall off after the fourth application and had completely disappeared before the fifth application when AD was observed. At this time point, physical intervention with a LLL was initiated. To prevent natural healing while LLLT was performed, 1.0\% DNCB solution $(150 \mu \mathrm{l})$ was applied to the backs of the mice once every three days $(33,34)$.
LLL irradiation. A diode laser therapy instrument (StraTek Co., Ltd.) at a wavelength of $650 \mathrm{~nm}$ and power of $50 \mathrm{~mW}$ was used for LLLT. The laser was emitted at a minimum intensity of $2 \mathrm{~J} / \mathrm{cm}^{2}$ and a maximum intensity of $8 \mathrm{~J} / \mathrm{cm}^{2}$. The scanning method was used for laser emission by setting the scanning speed to 'fast' in order to reproduce the same effect as that of a continuous laser emission.

An area of $3 \mathrm{~cm}^{2}$ on the back of each mouse was treated, and the energy density $\left(\mathrm{J} / \mathrm{cm}^{2}\right)$ was calculated from the laser output $(\mathrm{W})$, duration ( $\mathrm{sec}$ ) and therapeutic area $\left(\mathrm{J} / \mathrm{cm}^{2}\right)$ as follows (35): Energy density $=($ laser output $\mathrm{x}$ duration $) /$ therapeutic area.

There were six different groups in total. In the normal control group $(\mathrm{n}=8)$, only the solvent (acetone and olive oil mix in a 3:1 ratio; $200 \mu \mathrm{l}$ ) was applied to the backs of the mice. The five experiment groups were the following: One control group with induced AD $(n=10)$ and four experimental groups with induced $\mathrm{AD}$ followed by treatment with LLLT at difference energy density [Laser 2 at $2 \mathrm{~J} / \mathrm{cm}^{2}(\mathrm{n}=10)$; Laser 4 at $4 \mathrm{~J} / \mathrm{cm}^{2}$ $(\mathrm{n}=10)$; Laser 6 at $6 \mathrm{~J} / \mathrm{cm}^{2}(\mathrm{n}=9)$; and Laser 8 at $\left.8 \mathrm{~J} / \mathrm{cm}^{2}(\mathrm{n}=10)\right]$. Laser therapy was administered daily for two weeks (14 times in total).

Clinical skin severity test. Sensory evaluation is a clinical assessment involving physical examination. In total, two researchers performed this evaluation, and if there were differences, the results was determined via discussion. The outcome was represented as the sum of scores from five different categories. These five categories include erythema, pruritus and dry skin, edema and excoriation, erosion and lichenification. For each category, appropriate evaluation was performed and a score was assigned as follows: None (0), weak (1), intermediate (2) and severe (3). Subsequently, the final score ranged from 0 to $15(36,37)$.

After five applications of DNCB solution $(150 \mu 1)$, a clinical skin severity test of the mice was performed. A total of 13 mice with sensory evaluation scores of $\leq 12$ points were then excluded.

An LLL was emitted, at a wavelength of $650 \mathrm{~nm}$ and power of $50 \mathrm{~mW}, 14$ times in total over a 2-week period. Each group were exposed to each particular duration only (for 2, 4, 6 and $8 \mathrm{~min}$ each time/day). Sensory evaluation (clinical skin severity test) and a scratch test were performed at the following time points: Before therapy and at days 1, 3, 7 and 14 of therapy. On day 14 of therapy, the experiment was complete, and the mice were sacrificed via cervical dislocation after anesthesia. The serum levels of IgE and IL-4 and the mRNA expression of IL-4, IL-6, TNF- $\alpha$ and IFN- $\gamma$ were then evaluated. Finally, the tissues were stained using hematoxylin and eosin (H\&E) and toluidine blue to evaluate the tissue condition and mast cell count.

Scratch test. Scratching behavior was observed and the numbers of scratching episodes counted for 14 days. Scratching was evaluated using a slightly modified version of the traditional method, which was performed for $1 \mathrm{~h}$ from $30 \mathrm{~min}$ before and after application of the test substance $(37,38)$. The number of scratching movements made by the mice was measured during a 60-min time period before LLLT, a 30-min time period after LLLT, a 30-min time period after stabilization and a 30-min time period after $24 \mathrm{~h}$ on days 1, 3, 7 and 14 of LLLT. 
Measurement of serum IgE and IL-4 levels. On the last day of the experiment, $0.6-0.8 \mathrm{ml}$ of mouse blood was collected by cardiac puncture after euthanasia and left at room temperature to allow blood coagulation. The sample was centrifuged $\left(-18^{\circ} \mathrm{C}\right)$ at $1,000 \mathrm{x}$ f for $7 \mathrm{~min}$, and the separated serum was stored at $-80^{\circ} \mathrm{C}$.

IgE and IL-4 concentrations in mouse serum were measured by ELISA. Mouse IgE and IL-4 ELISA kits (cat. nos. 555248 and 555232; BD OptEIA ${ }^{\mathrm{TM}}$; BD Biosciences) were provided by BD Pharmingen; BD Biosciences. The ELISA plates were coated with coating buffer that contains the capture antibody, one day before the experiment. On the day of the experiment, the plate was washed with washing buffer containing $0.05 \%$ Tween-20 in PBS. The plates were blocked with PBS containing 10\% FBS (cat. no. FBS001-HI, Sigma-Aldrich; Merck KGaA). After additional washing with the washing buffer, $100 \mu \mathrm{l}$ of standard IgE and mouse serum were added into each well. After incubation at room temperature for $2 \mathrm{~h}$, the plate was washed, the detection antibody solution was added and the plate was incubated at room temperature for an additional $1 \mathrm{~h}$ for the reaction to occur. After the final wash with washing buffer, the substrate solution was added, and the plate was incubated in the dark. After $30 \mathrm{~min}$, the color was confirmed and $2 \mathrm{~N}$ sulfuric acid was added to stop the reaction. The optical density was measured at $450 \mathrm{~nm}$ on an ELISA plate reader to determine the concentrations of IgE and IL-4.

Weight of spleen. At the end of the experiment, the mice were sacrificed by cervical dislocation and the spleen was extracted. The weight of the spleen was evaluated using an Electronic Scale (cat. no. CP224S; Sartorius AG) $(33,39)$ and tissues were stored at $-80^{\circ} \mathrm{C}$.

Reverse transcription-quantitative (RT-q)PCR. The mRNA expression of IL-4, IL-6, TNF- $\alpha$, and IFN- $\gamma$ was evaluated in spleen tissues by RT-qPCR as previously described (40). Spleen tissues stored at $-80^{\circ} \mathrm{C}$ were thawed on ice and homogenized in an e-tube containing $1 \mathrm{ml}$ Total RNA isolation solution (RiboEX ${ }^{\mathrm{TM}}$; GeneAll Biotechnology Co., Ltd.) using a homogenizer. Gene extraction solution (GeneAll ${ }^{\circledR}$ Hybrid- ${ }^{\mathrm{TM}}$; GeneAllBiotechnology Co.,Ltd.) was used to extract RNA from the tissues. The concentration of extracted RNA was measured with a NanoDrop ND-1,000 Spectrometer (NanoDrop products), and cDNA was obtained using AccuPower ${ }^{\circledR}$ CycleScript RT PreMix (Bioneer Corporation). Samples were stored at $-80^{\circ} \mathrm{C}$ until further analysis. RT-qPCR was run using $\mathrm{SYBR}^{\circledR}$ Green (SolGent Co., Ltd.). RT-qPCR was performed. The sequences of the primers used are presented in Table I. The relative expression levels were normalized to endogenous control and were expressed as $2^{-\Delta \Delta C q}(41)$.

Histopathological analysis of mast cells and tissues. As soon as mice were sacrificed and at the end of the full protocol, mouse skin tissues from the lesions were biopsied from the backs of mice. To ensure that skin biopsies were performed at identical positions in all mice, the biopsies were collected from an area $\left(1.5 \times 1.5 \mathrm{~cm}^{2}\right)$ immediately above the line dividing the back of the mouse in half. Fixed tissues in $10 \%$ formalin $\left(18-20^{\circ} \mathrm{C}, 2\right.$ days) were embedded in paraffin and $5 \mu \mathrm{m}$-thick blocks were prepared. H\&E staining was subsequently
Table I. Sequence of the primers used for reverse transcription-quantitative PCR.

\begin{tabular}{ll}
\hline Gene & Sequences \\
\hline IL-4 & \\
Forward & 5'-AAGAACACCACAGAGAGTGAGCTC-3' \\
Reverse & 5'-TTTCAGTGATGTGGACTTGGACTC-3'
\end{tabular}

IL-6

Forward 5'-CAAGAGACTTCCATCCAGTTGC-3'

Reverse 5'-TTGCCGAGTAGATCTCAAAGTGAC-3'

TNF- $\alpha$

Forward 5'-ATGAGCACAGAAAGCATGATC-3'

Reverse 5'-TACAGGCTTGTCACTGGAATT-3'

IFN- $\gamma$

Forward 5'-GCCATCAGCAACAACATAAGCGTC-3'

Reverse 5'-CCACTCGGATGAGCTCATTGAATG-3'

\section{GAPDH}

Forward

5'-GAGGGGCCATCCACAGTCTTC-3'

Reverse 5'-CATCACCATCTTCCAGGAGCG-3'

IL-4, interleukin-4; IL-6, Interleukin-6; TNF- $\alpha$, Tumor necrosis factor- $\alpha$; IFN- $\gamma$, interferon- $\gamma$.

performed to identify edema and measure the epidermal thickness in different tissues. Toluidine blue staining was also used to identify mast cells and to observe any potential infiltration of mast cells into the tissues. The number of mast cells that were stained by toluidine blue within one square of the grid lines (magnification, x40 and x100, HNM005 HiMaxthe ${ }^{\circledR}$ ) was counted and the value was represented as cell count $/ \mathrm{mm}^{2}(42)$. When mast cells are activated, substances contained in granules, such as histamine, are degranulated, and lipid mediators such as cytokines, prostaglandins and leukotriene, are newly synthesized and secreted. These substances cause symptoms such as vasodilation, extravasation of white blood cells and inflammatory reactions (43). Therefore, the current experiment observed the number of granulated cells and degranulated cells.

Statistical analysis. All data were presented as the means \pm standard error of the mean. For evaluations involving temporal variables, including sensory evaluation and scratch test, two-way mixed repeated ANOVA was used followed by Bonferroni post hoc test. One-way ANOVA followed by Dunnett's post hoc test was used to compare the weights of the spleen and levels of IgE, IL-4, IL-6, TNF- $\alpha$ and IFN- $\gamma$ between different groups. $\mathrm{P}<0.05$ was considered to indicate a statistically significant difference. All statistical analyses were performed using GraphPad Prism software version 5.02 (GraphPad Software, Inc.).

\section{Results}

Effects of LLLT on the clinical skin severity and scratch tests. To understand the effects of LLL irradiation on sensory evaluation and scratching, mice were evaluated using a clinical skin 
A

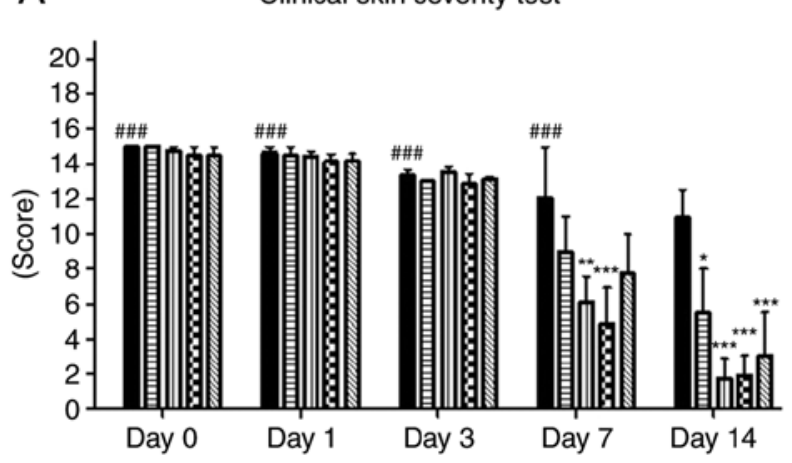

B

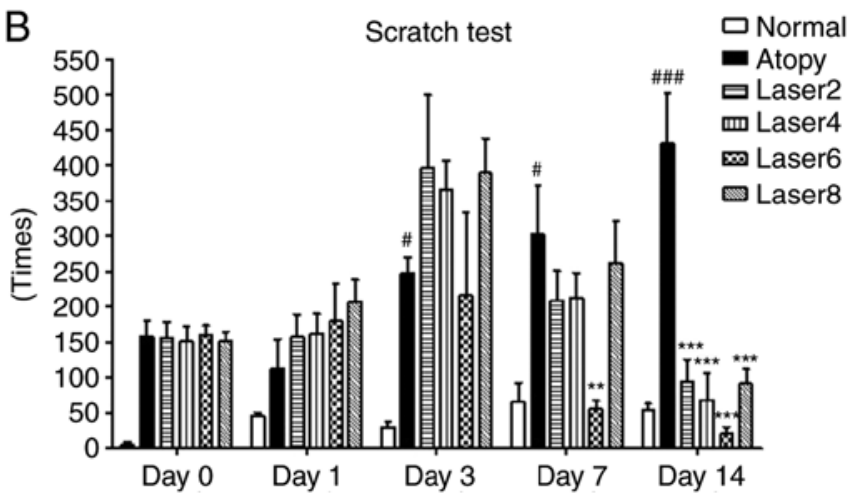

Figure 1. Effects of LLLT on the clinical skin severity and scratch tests. (A) Clinical skin severity test. (B) Scratch test. Day 0: Before Low Level Laser irradiation; Day 1: At days 1 of Low Level Laser irradiation; Day 3: At days 3 of Low Level Laser irradiation; Day 7: At days 7 of Low Level Laser irradiation; Day 14: At days 14 of Low Level Laser irradiation; Normal: Normal control group; Atopy: Only induced atopic dermatitis; Laser2 at $2 \mathrm{~J} / \mathrm{cm}^{2}$ ( $\mathrm{n}=10$ ); Laser4 at $4 \mathrm{~J} / \mathrm{cm}^{2}(\mathrm{n}=10)$; Laser6 at $6 \mathrm{~J} / \mathrm{cm}^{2}(\mathrm{n}=9)$; and Laser8 at $8 \mathrm{~J} / \mathrm{cm}^{2}(\mathrm{n}=10)$. ${ }^{*} \mathrm{P}<0.05,{ }^{* *} \mathrm{P}<0.01,{ }^{* * *} \mathrm{P}<0.001$ vs. Atopy; ${ }^{\#} \mathrm{P}<0.05,{ }^{\# \# \#} \mathrm{P}<0.001$ vs. Normal.
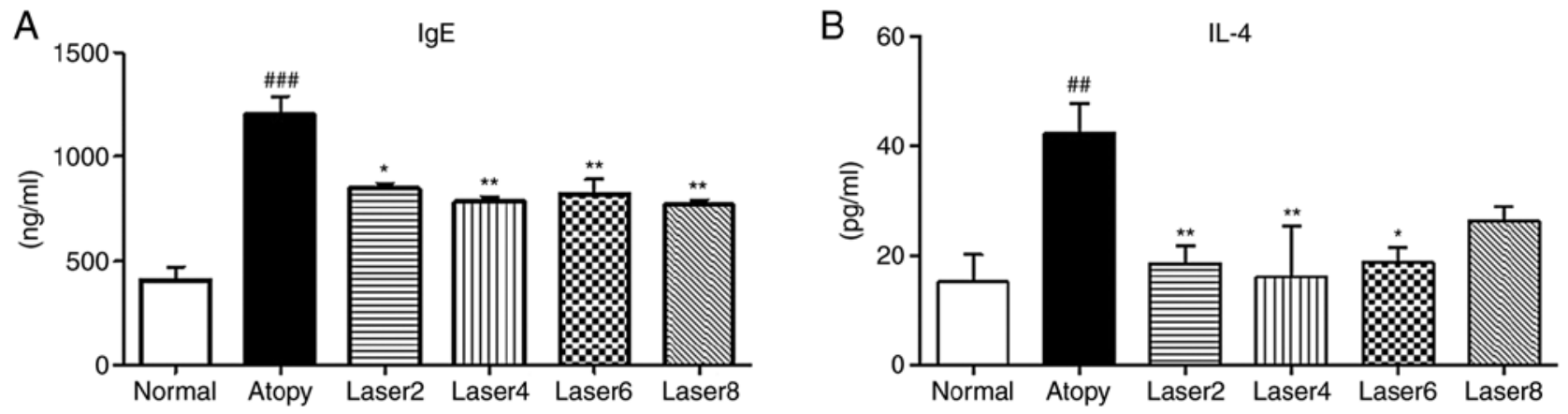

Figure 2. Effects of LLLT on serum IgE and IL-4 concentrations. (A) Effects of LLLT on serum IgE concentration. (B) IL4 concentration. Normal: Normal control group; Atopy: Only induced atopic dermatitis; Laser2 at $2 \mathrm{~J} / \mathrm{cm}^{2}(\mathrm{n}=10)$; Laser4 at $4 \mathrm{~J} / \mathrm{cm}^{2}(\mathrm{n}=10) ; \mathrm{Laser6}$ at $6 \mathrm{~J} / \mathrm{cm}^{2}(\mathrm{n}=9)$; and Laser8 at $8 \mathrm{~J} / \mathrm{cm}^{2}(\mathrm{n}=10)$. ${ }^{*} \mathrm{P}<0.05,{ }^{* *} \mathrm{P}<0.01$ vs. Atopy; ${ }^{\# \#} \mathrm{P}<0.01,{ }^{\# \# \#} \mathrm{P}<0.001$ vs. Normal.

severity test and a scratch test before LLLT and on days 1, 3, 7 and 14 of LLLT. From day 7 of LLLT, decrease in the clinical skin severity test in the Laser $4(\mathrm{P}<0.01)$ and Laser 6 groups $(\mathrm{P}<0.001)$ compared with the AD group was observed. Furthermore on day 7 of LLLT mice in the Laser 6 group showed significantly reduced scratching compared with the atopy group $(\mathrm{P}<0.01)$. By day 14 , all experimental groups exhibited significant decrease in scratching and the clinical skin severity test compared with the AD group $(\mathrm{P}<0.001$; Fig. 1).

Effects of LLLT on serum IgE and IL-4 concentrations. We measured the serum concentrations of IgE and IL-4 using ELISA in experimental mice with induced AD. In the AD control group, IgE concentration was significantly increased compared with normal control group $(\mathrm{P}<0.001)$. In addition, IgE concentration was significantly decreased in the experimental groups treated with LLLT compared with AD control group (Fig. 2A). Similarly, IL-4 concentration in the AD control group was significantly elevated compared with normal control group $(\mathrm{P}<0.01)$. Furthermore, IL-4 level was significantly decrease in all experimental groups treated with LLLT compared with AD control group ( $\mathrm{P}<0.01$; Fig. 2B).

Weight of spleen. The weight of the spleen was measured at the end of the experiments to determine the effect of
LLL on the immunization of laboratory animals caused by AD. The results demonstrated that the weight of spleen was significantly increased in the AD group compared with normal group $(\mathrm{P}<0.001)$. In addition, the experimental groups Laser $2(\mathrm{P}<0.001)$, Laser $4(\mathrm{P}<0.001)$, Laser $6(\mathrm{P}<0.001)$ and Laser $8 \mathrm{~J} / \mathrm{cm}^{2}(\mathrm{P}<0.01)$ exhibited significantly decreased spleen weight compared with AD control group (Fig. 3A).

Effects of LLLT on the mRNA expression of IL-4, IL-6, TNF- $\alpha$ and IFN- $\gamma$. The expression levels of IL-4, IL-6, TNF- $\alpha$ and IFN- $\gamma$ in experimental mice with induced AD were assessed using RT-qPCR. IL-6 and TNF- $\alpha$ expression levels in AD group were significantly increased compared with normal group. Moreover, IL-4 expression levels in AD group were not significantly increased compared with normal group, but IL-4 expression was significantly decreased in all experimental groups compared with AD group, except Laser 6 (Fig. 3B). IL- 6 and TNF- $\alpha$ expression was significantly decreased in all experimental groups compared with AD group (Fig. 3C and D).

Effects of LLLT on skin tissue. Changes in epidermal thickness, structure and number of mast cells in mouse tissues are presented in Fig. 4. The epidermal thickness was determined in all tissues. The results revealed a significant increase in epidermal thickness in the AD control group compared with the normal group $(\mathrm{P}<0.001)$. Furthermore, all experimental 
A

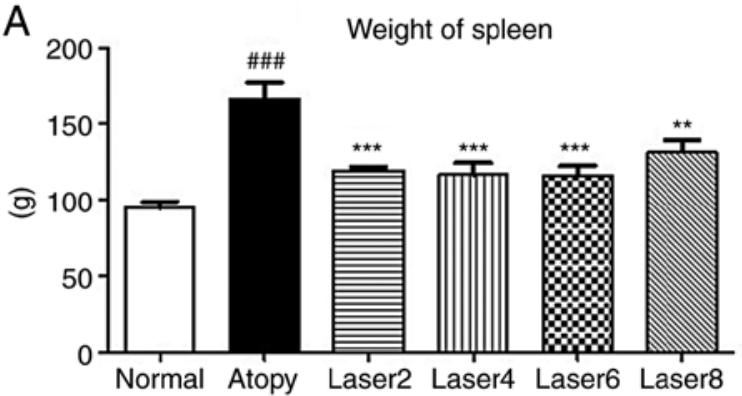

C

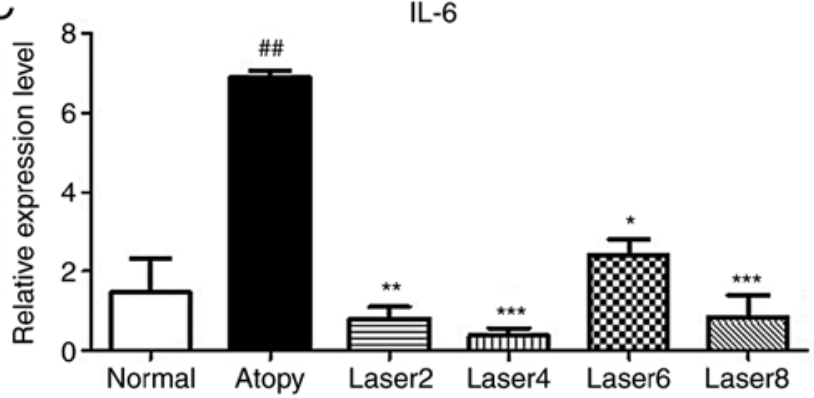

$\mathrm{B}$

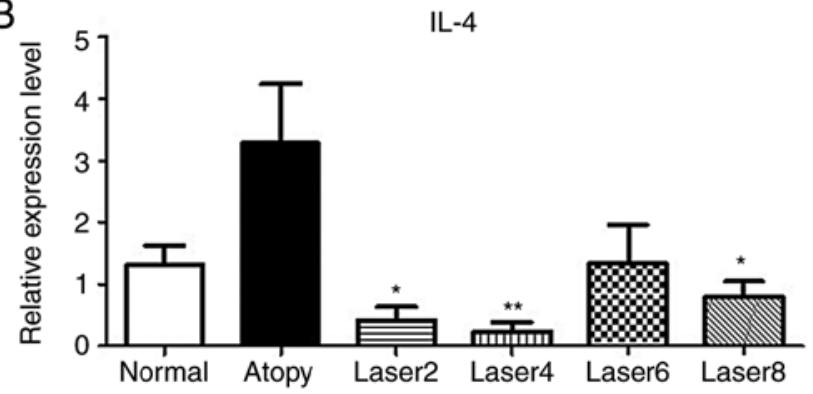

D

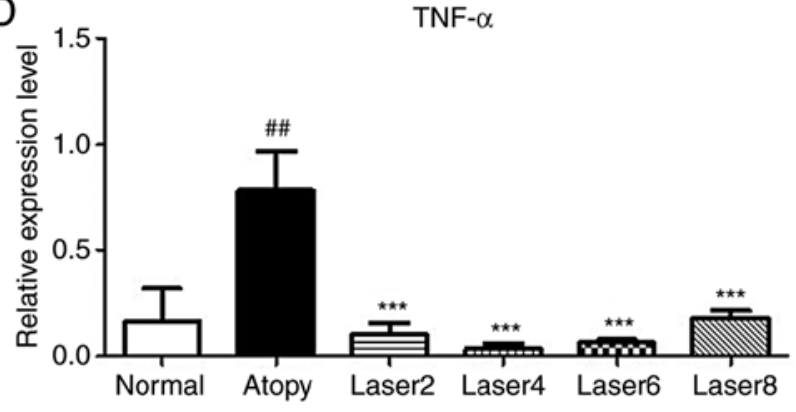

Figure 3. Weight of spleen and mRNA expression levels. (A) Effects of LLLT on weight of spleen. Effects of LLLT on mRNA expression levels of (B) IL4, (C) IL-6 and (D) TNF- $\alpha$. Normal: Normal control group; Atopy: Only induced atopic dermatitis; Laser2 at $2 \mathrm{~J} / \mathrm{cm}^{2}(\mathrm{n}=10) ;$ Laser4 at $4 \mathrm{~J} / \mathrm{cm}^{2}(\mathrm{n}=10) ;$ Laser6 at $6 \mathrm{~J} / \mathrm{cm}^{2}(\mathrm{n}=9)$; and Laser8 at $8 \mathrm{~J} / \mathrm{cm}^{2}(\mathrm{n}=10)$. ${ }^{*} \mathrm{P}<0.05,{ }^{* *} \mathrm{P}<0.01,{ }^{* * * *} \mathrm{P}<0.001$ vs. Atopy; ${ }^{\# \#} \mathrm{P}<0.01,{ }^{\# \# \#} \mathrm{P}<0.001$ vs. Normal. IL-4, interleukin-4; IL-6, interleukin-6; TNF- $\alpha$, tumor necrosis factor- $\alpha$.

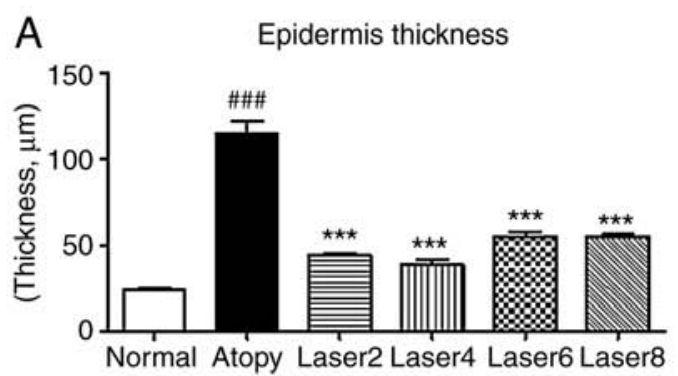

C

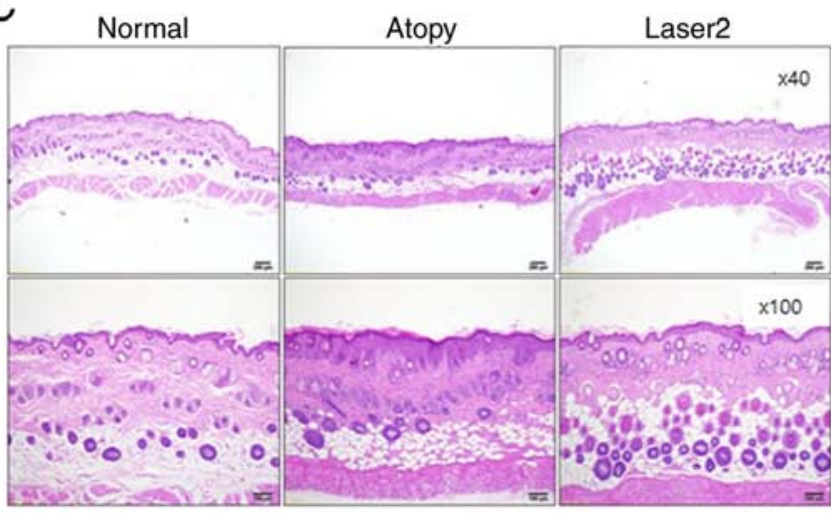

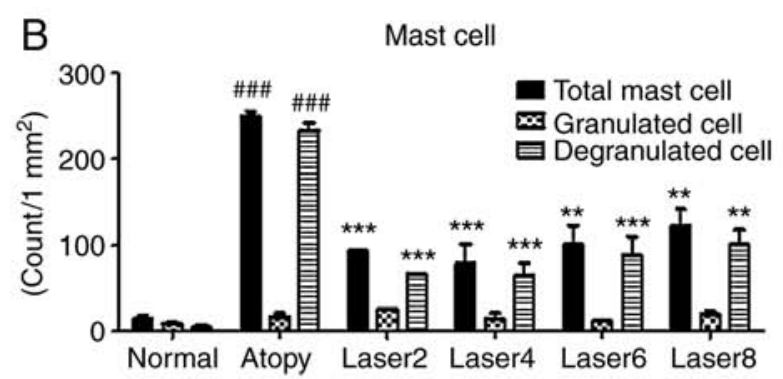

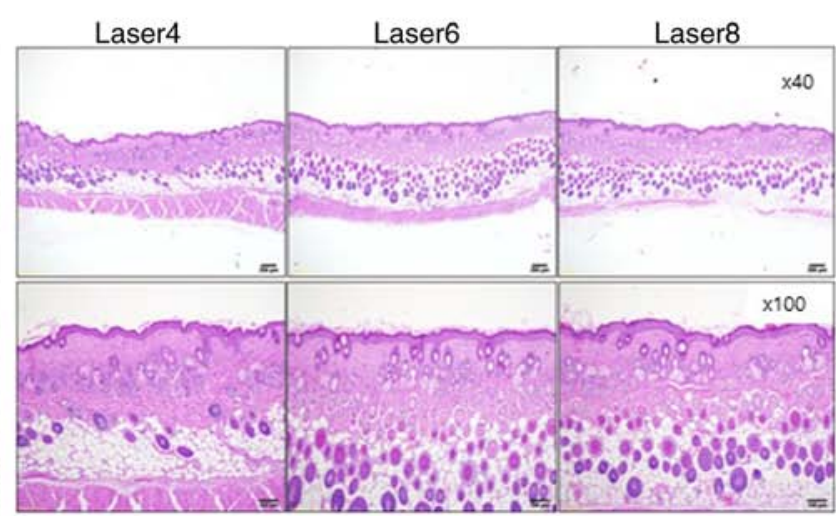

Figure 4. Effects of LLLT on skin tissue. (A) Changes in epidermal thickness. (B) Number of mast cells in the tissue. (C) Histopathological analyses of mast cells and tissues (magnification, $\mathrm{x} 40 \mathrm{x} 100$ ). Normal: Normal control group; Atopy: Only induced atopic dermatitis; Laser2 at $2 \mathrm{~J} / \mathrm{cm}^{2}$ ( $\mathrm{n}=10$ ); Laser4 at $4 \mathrm{~J} / \mathrm{cm}^{2}$ $(\mathrm{n}=10)$; Laser6 at $6 \mathrm{~J} / \mathrm{cm}^{2}(\mathrm{n}=9)$; and Laser8 at $8 \mathrm{~J} / \mathrm{cm}^{2}(\mathrm{n}=10) .{ }^{* *} \mathrm{P}<0.01,{ }^{* * *} \mathrm{P}<0.001$ vs. Atopy; ${ }^{\# \#} \mathrm{P}<0.001$ vs. Normal.

groups treated with LLLT exhibited significantly reduced epidermal thickness compared with the AD group $(\mathrm{P}<0.001)$. Furthermore, according to results from H\&E staining, the AD group showed increased epidermal and dermal thickness, as well as markedly increased hyperkeratinization near the lesion, compared with the normal group. Furthermore, the experimental groups treated with LLLT showed decreased epidermal and dermal thickness similar to that of the normal group, and the hyperkeratinization was improved.

The total number of mast cells, granulated and degranulated cells within an area of $1 \mathrm{~mm}^{2}$ of the tissues was subsequently assessed in all tissues. The results demonstrated 
that the total number of mast cells in the experimental groups treated with LLLT was significantly lower compared with that in the AD group $(\mathrm{P}<0.001)$. The number of granulated cells in the AD control group was slightly higher than that in the normal group. The experimental groups treated with LLLT presented similar numbers of granulated cells to that in the AD group. The number of degranulated cells in the AD group was significantly increased compared with the normal group $(\mathrm{P}<0.001)$. In addition, the experimental groups treated with LLLT exhibited a significantly decreased number of degranulated cells compared with the AD control group $(\mathrm{P}<0.001)$.

\section{Discussion}

The effects of LLLT on relieving the symptoms of dermatitis have been previously demonstrated in clinical settings $(17,44)$. The present study attempted therefore to confirm the curative effect of a 'designed' energy irradiation dose of LLL towards AD.

The wavelength used in the present study was $650 \mathrm{~nm}$, which is within the range of suggested wavelengths $(630-660 \mathrm{~nm})$ for inflammation therapy (45). It has been reported that LLL at $1-6 \mathrm{~J} / \mathrm{cm}^{2}$ is effective against acute and subacute inflammations, while LLL at $4-8 \mathrm{~J} / \mathrm{cm}^{2}$ is effective against chronic inflammations, such as atopic dermatitis and arthritis (35). According to the World Association for Laser Therapy, the red wavelength doses used for superficial diseases tend to be $\sim 4 \mathrm{~J} / \mathrm{cm}^{2}$ (32). The present study used therefore laser outputs of 2, 4, 6 and $8 \mathrm{~J} / \mathrm{cm}^{2}$.

In the present study, the results from sensory evaluation, which evaluates the therapeutic effectiveness by assigning scores to different symptoms of AD, demonstrated that after 7 days of LLLT, the experimental groups treated with LLLT exhibited significantly decreased symptoms compared with the AD group.

In the present study, a scratch test was performed following treatment with LLLT. The results demonstrated that the AD group exhibited increased scratching from day 3. All experimental groups treated with LLLT exhibited increased scratching on day 3 , followed by significantly decreased scratching on days 7 and 14 compared with the AD group. The smallest decrease in scratching was observed in the Laser 6 group.

In the present study, the onset of AD was confirmed by changes in serum IgE and IL-4 concentrations. In previous studies, it was demonstrated that LLLT can suppress the induction of AD $(1,32,36)$. In addition, IL-4 serum concentration in mice with induced AD was significantly elevated compared with that in mice in the normal group. These findings were similar to previous studies, which demonstrated that the level of the Th2 cell cytokine IL-4 is elevated in patients with AD (1,6,36). In the present study, except for the Laser 8 group, all experimental groups treated with LLLT, showed significant reduction in serum IL-4 concentration compared with the AD group. The Laser 4 group exhibited the most efficient reduction. These findings indicated that laser therapy was effective for relieving symptoms of AD.

As described in previous studies $(33,39)$, the weight of spleen in the present study was measured and the immune response in mice with $\mathrm{AD}$ was analyzed. The results demonstrated that mice in the AD groups had increased spleen weight. However, the weight of spleen decreased significantly in all laser irradiation groups compared with than in the AD group, Increased spleen weight is associated with increased T lymphocytes. However, a decreased weight means a decrease in inflammatory reactions by $\mathrm{T}$ lymphocytes (39). Thus, these findings suggested that LLLT may have an effect on immunity.

Subsequently, the expression of some mRNA was assessed in spleen tissues. In humans, $\sim 10-15 \%$ of the lymphocytes in the blood, $20-25 \%$ of the lymphocytes in the lymph nodes and $\sim 40-45 \%$ of the lymphocytes in the spleen cells are B cells (46); the spleen has therefore the largest amount of lymphocytes. If taken from the blood, cytokines, represented by white blood cells, may also be sensitive to differences in blood collection or sample manipulation methods (47). Quantitative analysis of cytokine mRNA expression levels suggests that these cytokines can be considered as potential sensitive markers for determination of the state of immune cell activation (48). In present study, total RNA was extracted from the spleen tissues of each group, and the mRNA expression of IL-4, IL- 6 and TNF- $\alpha$ (factors of Th 2 immune response) and IFN- $\gamma$ (factor of Th1 immune response) was evaluated. Th1 and Th2 cells maintain immune balance, where IL-4 suppresses the Th1 type reaction and IFN- $\gamma$ suppresses the Th2 type reaction (1). T-cells in patients with $\mathrm{AD}$ have decreased ability to produce IFN- $\gamma$ and are highly reactive to IL-4, which is thought to be the main reason for immune response by type Th2 cells in AD (1). The present study assessed the mRNA expression of IL-4, IL-6, TNF- $\alpha$ and IFN- $\gamma$ (data not shown) after LLLT treatment. The expression levels of IL-4, IL-6 and TNF- $\alpha$ were significantly increased in the AD group, which has been previously described (3-6). Since IL-4 is the cytokine responsible for $\operatorname{IgE}$ release in $\mathrm{AD}$, patients with AD exhibit elevated levels of IL-4. In addition, increased IL- 6 and TNF- $\alpha$ levels in AD have been reported in several studies $(1,6,8,9,45,49,50)$. Subsequently, the increased mRNA expression of these cytokines described in the present study indicated that AD was successfully induced. Furthermore, following LLLT treatment, the expression level of IL-4 was significantly decreased in all experimental groups except for the Laser 6 group. Among these groups, the Laser 4 group exhibited the lowest IL-4 mRNA expression. In addition, the IL-6 expression level was decreased in all experimental groups treated with LLLT, with Laser 4 group presenting the lowest IL-6 expression level. Furthermore, the mRNA expression of TNF- $\alpha$ in all experimental groups treated with LLLT was significantly decreased compared with that in the AD group. Once again, the Laser 4 group showed the lowest expression level of TNF- $\alpha$. Atopic dermatitis is caused by abnormal activation of IL4, the Th2 cytokine (1). These findings suggested that LLLT may suppress the immune response from Th2 cells, subsequently reducing the inflammatory response in AD.

The current study also measured the expression of IFN- $\gamma$ and observed lower expression level of IFN- $\gamma$; however, the difference was not significant. Since IFN- $\gamma$ is the cytokine that induces immune responses from Th1 cells (51), these findings indicated that AD treatment with LLLT for two weeks was not sufficient to correct the immune imbalance between Th1 and Th2 cells. 
The epidermal thickness of AD lesions was assessed by H\&E staining. The results showed a significant reduction in epidermal thickness in the experimental groups treated with LLLT, particularly in the Laser 4 group that exhibited the greatest reduction, compared with the AD group. Furthermore, the number of mast cells after toluidine blue staining in the AD groups was significantly increased compared with the normal group. In addition, the number of degranulated cells in the AD control group was significantly higher than in all experimental groups treated with LLLT. This observation was due to the larger number of mast cells in this group. These findings suggested that LLLT may be considered as an effective treatment option for AD.

The wavelength of LLL used in this study $(650 \mathrm{~nm})$ could effectively recover inflammation Although $1.0 \%$ DNCB solution was frequently applied to prevent natural healing of AD, all experimental groups treated with LLLT exhibited decreased IL-4, IL-6, and TNF- $\alpha$ levels. Immunomodulation by the Th1 and Th2 cells might have accounted for the elevated IFN- $\gamma$ expression level in the AD group compared with that in the other experimental groups treated with LLLT. However, the present results indicated that gene expression of IFN- $\gamma$ in the AD control group did not differ from that in the other experimental groups treated with LLLT (data not shown). Therefore, the AD improvement observed in this study did not result from immunomodulation by the Th1 and Th2 cells, but rather from the intracellular activity promoted by LLLT to induce recovery of inflammation and skin restoration (52) and to reduce the mRNA expression of IL-4, IL- 6 and TNF- $\alpha$. Future investigation on immunomodulation by the Th1 and Th2 cells is therefore required.

The findings from the present study suggested that LLLT may be considered as an effective treatment for AD since it may promote intracellular activation to reduce the release of inflammatory cytokines from Th2 cells. Furthermore, comparisons of the different treatment group outcomes suggested that the $4 \mathrm{~J} / \mathrm{cm}^{2}$ laser output was more effective at improving the symptoms of $\mathrm{AD}$ and reducing the levels of cytokines compared with other output values.

The present study evaluated the changes in clinical skin severity and scratching for 14 days. Further investigation will therefore investigate IgE and IL-4 levels evolution over time. IgE was evaluated because it is directly related to inflammation. Furthermore, histamine is released when allergy antigens bind to IgE antibodies that bind to obese cells. Increased $\operatorname{IgE}$ leads to histamine release, causing inflammatory reactions. Histamine is one of the organic substances that the body secretes for rapid defense against external stimulation (stress). In other words, it is a substance that causes inflammation, in which the wound swells red and causes pain (53). Therefore, IgE overproduction may be associated with the release of high levels of histamine. The present study identified how LLL irradiation affects IgE and cytokines (IL-4, IL-6 and TNF- $\alpha$ ) in the skin that caused atopic dermatitis. Future investigation will therefore examine the release of histamine in this model.

Since the number of experimental animals used in this study was relatively low, Clinical research, including a large number of animal trials, will be needed. Taken together, the findings from the present study may help determining clinically appropriate energy outputs for LLLT against AD.

\section{Acknowledgements}

The authors would like to thank Dr Miyung Kim, Dr June Bryan, Dr Irene Joy, Dr Chrislean Jun and Dr Raly James (Uimyung Research Institute. Sahmyook University) for their assistance preparing animal experiuments and their support on this paper.

\section{Funding}

This study was supported by a grant from Sahmyook University in 2017.

\section{Availability of data and materials}

The datasets used and/or analyzed during the current study are available from the corresponding author on reasonable request.

\section{Authors' contributions}

YLK and HSL carry out the experiments. YLK and HSL analyzed and interpreted the data regarding the cytokines. YLK and SML made substantial contributions to conception and design of the study, and confirmed the authenticity of all the raw data. All authors read and approved the final manuscript

\section{Ethics approval and consent to participate}

This study was approved by the Animal Research Ethics Board of Sahmyook University (approval no. SYUIACUC2017-004).

\section{Patient consent for publication}

Not applicable.

\section{Competing interests}

The authors declare that they have no competing interests.

\section{References}

1. Bieber T: Atopic dermatitis. Ann Dermatol 22: 125-137, 2010.

2. Sandstrom MH and Faergemann J: Prognosis and prognostic factors in adult patients with atopic dermatitis: A long-term follow-up questionnaire study. Br J Dermatol 150: 103-110, 2004

3. Youssef DM, Elbehidy RM, El-Shal AS and Sherief LM: T helper 1 and T helper 2 cytokines in atopic children with steroidsensitive nephrotic syndrome. Iran J Kidney Dis 9: 298-305, 2015.

4. Hanzlikova J, Ulcova-Gallova Z, Malkusova I, Sefrna F and Panzner P: TH1-TH2 response and the atopy risk in patients with reproduction failure. Am J Reprod Immunol 61: 213-220, 2009.

5. Horsmanheimo L, Harvima IT, Jarvikallio A, Harvima RJ, Naukkarinen A and Horsmanheimo M: Mast cells are one major source of interleukin-4 in atopic dermatitis. Br J Dermatol 131: 348-353, 1994.

6. Jung JH and Kim GJ: Anti-inflammatory effects of herbal medicines (Rubus coreanus, Rehmanniae Radix, Houttuynia cordata, Betulae cortex) EtOH extract on acute atopic dermatitis mice. J Korean Med Ophthalmol Otolaryngol Dermatol 28: 68-84, 2015.

7. Lim YY, Kim HM, Jang WS, Seo SH, Ahn HH, Kim Mn and Kim BJ: Study on tests of skin safety and inhibition of atopic dermatitis using a StoneTouch ${ }^{\circledR}$ infrared scanner in a mouse model. Korean J Dermatol 49: 217-226, 2011.

8. Lim YY, Jang WS, Kim HM, Kim IS, Lee JW, Kim MN and Kim BJ: Therapeutic effects of light emitting diode on atopic dermatitis-like lesions in NC/Nga mice. Korean J Asthma Allergy Clin Immunol 31: 207-214, 2011. 
9. Kwon TR: UV-LED 310-nm and 340-nm of phototherapy in the treatment of atopic dermatitis. PhD Thesis, Chung-Ang University, Seoul, Korea, 2015.

10. Garritsen FM, Brouwer MW, Limpens J and Spuls PI: Photo(chemo)therapy in the management of atopic dermatitis: An updated systematic review with implications for practice and research. Br J Dermatol 170: 501-513, 2014

11. Jekal SJ, Park MS and Kim DJ: The combined effects of curcumin administration and $630 \mathrm{~nm}$ LED phototherapy against DNCB-induced atopic dermatitis-like skin lesions in BALB/c mice. Korean J Clin Lab Sci 49: 150-160, 2017.

12. de Freitas LF and Hamblin MR: Proposed mechanisms of photobiomodulation or low-level light therapy. IEEE J Sel Top Quantum Electron 22: 7000417, 2016.

13. Yu W, Naim JO and Lanzafame RJ: Effects of photostimulation on wound healing in diabetic mice. Lasers Surg Med 20: 56-63, 1997.

14. Barber AJ, Luger E and Karpfetal A: Advances in laser therapy for bone repair. Laser Ther 13: 84-85, 2000.

15. Hamblin MR and Demidova TN: Mechanisms of low level light therapy. In: Mechanisms for Low-Light Therapy. Hamblin MR, Waynant RW and Anders J (eds). Proceedings of SPIE. Vol 6140 1-12, 2006.

16. Kim KU: Effects of low level laser irradiation with $904 \mathrm{~nm}$ pulsed diode laser on the extraction wound. J Korean Academy of Oral Med 23: 301-309, 1998.

17. Marei MK, Abdel-Meguid SH, Mokhtar SA and Rizk SA: Effect of low-energy laser application in the treatment of denture-induced mucosal lesions. J Prosthet Dent 77: 256-264, 1997.

18. Joon YH, Sung YJ, Gon KD and Yong LJ: The effects of low level laser therapy on decrease of atopic dermatitis symptoms. Korean J Pediatr Med 23: 193-206, 2009.

19. Clokie C, Bentley KC and Head TW: The effects of the helium-neon laser on postsurgical discomfort: A pilot study. J Can Dent Assoc 57: 584-586, 1991.

20. Kert J: Low level laser therapy used pre-operatively. Laser News 4: 26-32, 1992.

21. Roynesdal AK, Bjornland T, Barkvoll $\mathrm{P}$ and Haanaes HR: The effect of soft-laser application on postoperative pain and swelling. A double-blind, crossover study. Int J Oral Maxillofac Surg 22: 242-245, 1993.

22. Pick RM and Powell GL: Laser in dentistry: Soft tissue procedure. Dent Clin North Am 37: 281-296, 1993.

23. Miller M and Truhe T: Lasers in dentistry: An overview. J Am Dent Assoc 124: 32-55, 1993.

24. Hall J, Clarke AK, Elvins DM and Ring EF: Low level laser therapy is ineffective in the management of rheumatoid arthritic finger joints. Br J Rheumatol 33: 142-147, 1994.

25. Basford JR: Laser therapy: Scientific basis and clinical role. Orthopedics 16: 541-547, 1993.

26. Beckerman H, de Bie RA, Bouter LM, De Cuyper HJ and Oostendorp RA: The efficacy of laser therapy for musculoskeletal and skin disorders: A criteria-based meta-analysis of randomized clinical trials. Phys Ther 72: 483-491, 1992.

27. Morita H, Kohno J, Hori M and Kitano Y: Clinical application of low reactive level laser therapy (LLLT) for atopic dermatitis. Keio J Med 42: 174-176, 1993.

28. Nistico SP, Saraceno R, Capriotti E, Felice CD and Chimenti S: Efficacy of monochromatic excimer light $(308 \mathrm{~nm})$ in the treatment of atopic dermatitis in adults and children. Photomed Laser Surg 26: 14-18, 2008.

29. Baltas E, Csoma Z, Bodai L, Ignacz F, Dobozy A and Kemeny L: Treatment of atopic dermatitis with the xenon chloride excimer laser. J Eur Acad Dermatol Venereol 20: 657-660, 2006

30. Brenninkmeijer EE, Spuls PI, Lindeboom R, van der Wal AC, Bos JD and Wolkerstorfer A: Excimer laser vs. Clobetasol propionate $0.05 \%$ ointment in prurigo form of atopic dermatitis: A randomized controlled trial, a pilot. Br J Dermatol 163: 823-831, 2010.

31. Syed S, Weibel L, Kennedy $\mathrm{H}$ and Harper JI: A pilot study showing pulsed-dye laser treatment improves localized areas of chronic atopic dermatitis. Clin Exp Dermatol 33: 243-248, 2008.

32. Stich AN, Rosenkrantz WS and Griffin CE: Clinical efficacy of low-level laser therapy on localized canine atopic dermatitis severity score and localized pruritic visual analog score in pedal pruritus due to canine atopic dermatitis. Vet Dermatol 25 : 464-474, 2014
33. Lee KS, Jeong ES, Hea SH, Seo JH, Jeong DG and Choi YK: A novel model for human atopic dermatitis: Application of repeated $\mathrm{DNCB}$ patch in $\mathrm{BALB} / \mathrm{c}$ mice, in comparison with $\mathrm{NC} / \mathrm{Nga}$ mice. Lab Anim Res 26: 95-102, 2010.

34. Suto H, Matsuda H, Mitsuishi K, Hira K, Uchida T, Unno T, Ogawa $\mathrm{H}$ and $\mathrm{Ra} \mathrm{C}$ : NC/Nga mice: A mouse model for atopic dermatitis. Int Arch Allergy Immunol 120 (Suppl 1): 70-75, 1999.

35. Kim SH: Phototherapy. Hanlddlag, Gunggido, p198, 2005.

36. Suzuki R, Shimizu T, Kudo T, Ohtsuka Y, Yamashiro Y and Oshida K: Effects of n-3 polyunsaturated fatty acids on dermatitis in NC/Nga mice. Prostaglandins Leukot Essent Fatty Acids 66: 435-440, 2002

37. Lee GS, Jung HM, Oh SK, Cheong JH and Kang TJ: Effects of herbal complex on atopic dermatitis in BALB/c mice. Kor J Pharmacogn 43: 59-65, 2012

38. Umeda K, Noro Y, Murakami T, Tokime K, Sugisaki H, Yamanaka K, Kurokawa I, Kuno K, Tsutsui H, Nakanishi K and Mizutani H: A novel acoustic evaluation system of scratching in mouse dermatitis: Rapid and specific detection of invisibly rapid scratch in an atopic dermatitis model mouse. Life Sci 79: 2144-2150, 2006.

39. Ahn JY, Lee RI, Kim JH, Park JH, Kim DK and Lee YM: Effects of rumecis radix water extract on development of atopic dermatitis in BALB/c Mice. Korean J Pharmacogn 40: 218-223, 2009.

40. Kim M, Custodio RJ, Botanas CJ, de la Peña JB, Sayson LV, Abiero A, Ryoo ZY, Cheong JH and Kim HJ: The circadian gene, Per2, influences methamphetamine sensitization and reward through the dopaminergic system in the striatum of mice. Addict Biol 24: 946-957, 2019.

41. Livak KJ and Schmittgen TD. Analysis of relative gene expression data using real-time quantitative PCR and the 2(-delta delta C(T)) method. Methods 25: 402-408, 2001.

42. Choy DF, Hsu DK, Seshasayee D, Fung MA, Modrusan Z, Martin F, Liu FT and Arron JR: Comparative transcriptomic analyses of atopic dermatitis and psoriasis reveal shared neutrophilic inflammation. J Allergy Clin Immunol 130: 1335-1343.e5, 2012.

43. Owen J, Punt J and Stratford S: Kuby Immunology. 7th edition. W.H. Freemand and Company, New York, NY, USA, p372, 2013.

44. Moreira MS, Velasco IT, Ferreira LS, Ariga SK, Abatepaulo F, Grinberg LT and Marques MM: Effect of laser phototherapy on wound healing following cerebral ischemia by cryogenic injury. J Photochem Photobiol B 105: 207-215, 2011.

45. Cooper D, Hales J and Camp R: IgE-dependent activation of T cells by allergen in atopic dermatitis: Pathophysiologic relevance. J Invest Dermatol 123: 1086-1091, 2004.

46. Abbas AK and Andrew H: Lichtmann, Shiv Pillai: Cellular and Molecular Immunology. 6 edition. Saunders Elsevier, Philadelphia, p50, 2007

47. Hartel C, Bein G, Muller-Steinhardt M and Kluter H: Ex vivo induction of cytokine mRNA expression in human blood samples. J Immuno Methods 249: 63-71, 2001.

48. Whiteside TL: Cytokines and cytokine measurements in clinical laboratory. Clin Diagn Lab Immunol 1: 257-266, 1994.

49. Taniuchi S, Kojima T, Hara Mt K, Yamamoto A, Sasai M, Takahashi $\mathrm{H}$ and Kobayashi $\mathrm{Y}$ : Increased serum nitrate levels in infants with atopic dermatitis. Allergy 56: 693-695, 2001.

50. Homey B, Steinhoff M, Ruzicka T and Leung DY: Cytokines and chemokines orchestrate atopic skin inflammation. J Allergy Clin Immunol 118: 178-189, 2006.

51. Abbas AK, Lichtman AH and Pober JS: Cellular and Molecular Immunology. Bummoon-Education, Seoul, pp320-321, 1998.

52. Huang YY, Sharma SK, Carroll J and Hamblin MR: Biphasic dose response in low level light therapy-an update. Dose Response 9: 602-618, 2011

53. MacDonald SM, Rafnar T, Langdon J and Lichtenstein LM: Molecular identification of an IgE-dependent histamine-releasing factor. Science 269: 688-690, 1995.

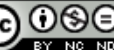

This work is licensed under a Creative Commons Attribution-NonCommercial-NoDerivatives 4.0 International (CC BY-NC-ND 4.0) License. 